\title{
Remote-controlled cholangiography injection device: first clinical study in China
}

\author{
Huan Chen ${ }^{1,3}$, Li-yu Shan ${ }^{1,4}$, Tao Ma1, Yue Wang ${ }^{1}$, Zhe Feng ${ }^{1,4}$, Ding-Hui Dong ${ }^{1,4}$, Yi Lv ${ }^{1,4}$ and Hao-Yang Zhu ${ }^{1,2^{*}}$
}

\begin{abstract}
Background: X-ray cholangiography is of great value in the imaging of biliary tract diseases; however, occupational radiation exposure is unavoidable. Moreover, clinicians must manually inject the contrast dye, which may result in a relatively high incidence of adverse reactions due to unstable injection pressure. Thus, there is a need to develop a novel remote-controlled cholangiography injection device.

Methods: Patients with external biliary drainage requiring cholangiography were included. A remote-controlled injection device was developed with three major components: an injection pump, a pressure sensor, and a wireless remote-control panel. Image quality, adverse reactions, and radiation dose were evaluated.
\end{abstract}

Results: Different kinds of X-ray cholangiography were successfully and smoothly performed using this remotecontrolled injection device in all patients. The incidence of adverse reactions in the device group was significantly lower than that in the manual group $(4.17 \%$ vs. $13.9 \%, P=0.001)$, and increasing the injection pressure increased the incidence of adverse reactions. In addition, the device helped operators avoid ionizing radiation completely.

Conclusions: With good control of injection pressure (within $10 \mathrm{kPa}$ ), the remote-controlled cholangiography injection device could replace the need for the doctor to inject contrast agent with good security and effectivity. It is expected to be submitted for clinical application.

Keywords: Cholangiography, Equipment design, Remote control technology, Injection device, Occupational exposure

\section{Background}

Biliary tract diseases are common in hepatobiliary surgery, with the incidence of gallstones alone reaching up to $10 \%$ [1]. In addition, the biliary tract is complicated, with anatomical variations present in approximately 35\% of patients. Consequently, there are great challenges in the diagnosis and treatment of biliary tract diseases [24]. In clinical work, the diagnosis of biliary tract diseases depends on the use of a variety of imaging examinations [5], including B-mode ultrasonography [6], computed

\footnotetext{
*Correspondence: 243207060@qq.com

${ }^{1}$ National Local Joint Engineering Research Center for Precision Surgery and Regenerative Medicine, First Affiliated Hospital of Xi'an Jiaotong University, Xi'an 710061, China

Full list of author information is available at the end of the article
}

tomography $(\mathrm{CT})[7,8]$, magnetic resonance cholangiopancreatography (MRCP) $[9,10]$ and X-ray cholangiography [11]. Among them, X-ray cholangiography, wherein the biliary tract is injected with a medical contrast agent under X-ray to reveal lesions, is of great value $[12,13]$. Compared with other biliary display technologies, cholangiography is simpler, more convenient, and cheaper and provides real-time kinematic imaging, which other imaging modalities cannot.

However, traditional cholangiography must be performed under X-ray, and a lead suit cannot fully protect the operator against radiation $[14,15]$. Therefore, occupational exposure to radiation remains a detrimental side-effect. Additionally, radiation of unprotected areas such as the eyes and hands could cause cataracts, skin damage, or even cancer [16]. 
Furthermore, cholangiography requires the clinician to inject contrast dye into the biliary tract; therefore, the injection speed and injection pressure are controlled manually, and the intrabiliary pressure is not monitored. Consequently, it is difficult to maintain a consistent injection speed and pressure, which could cause a high incidence of adverse reactions $(5-13 \%$ in different medical centers) [17].

To solve the aforementioned problems, our team developed a novel remote-controlled cholangiography injection device, the feasibility of which has been shown in animal experiments [18]. In this study, we report the successful application of this device in the clinic. The purpose of this study was to verify the safety and efficacy of the device in clinical applications.

\section{Methods \\ Study design and patients}

The design of this study is shown in Fig. 1. From January 2018 to September 2018, 268 patients with percutaneous biliary tubes who needed cholangiography were selected from the First Affiliated Hospital of Xi'an Jiaotong University to undergo cholangiography using our remotecontrolled cholangiography injection device. From July 2017 to December 2017, 279 patients with percutaneous biliary tubes undergoing traditional cholangiography

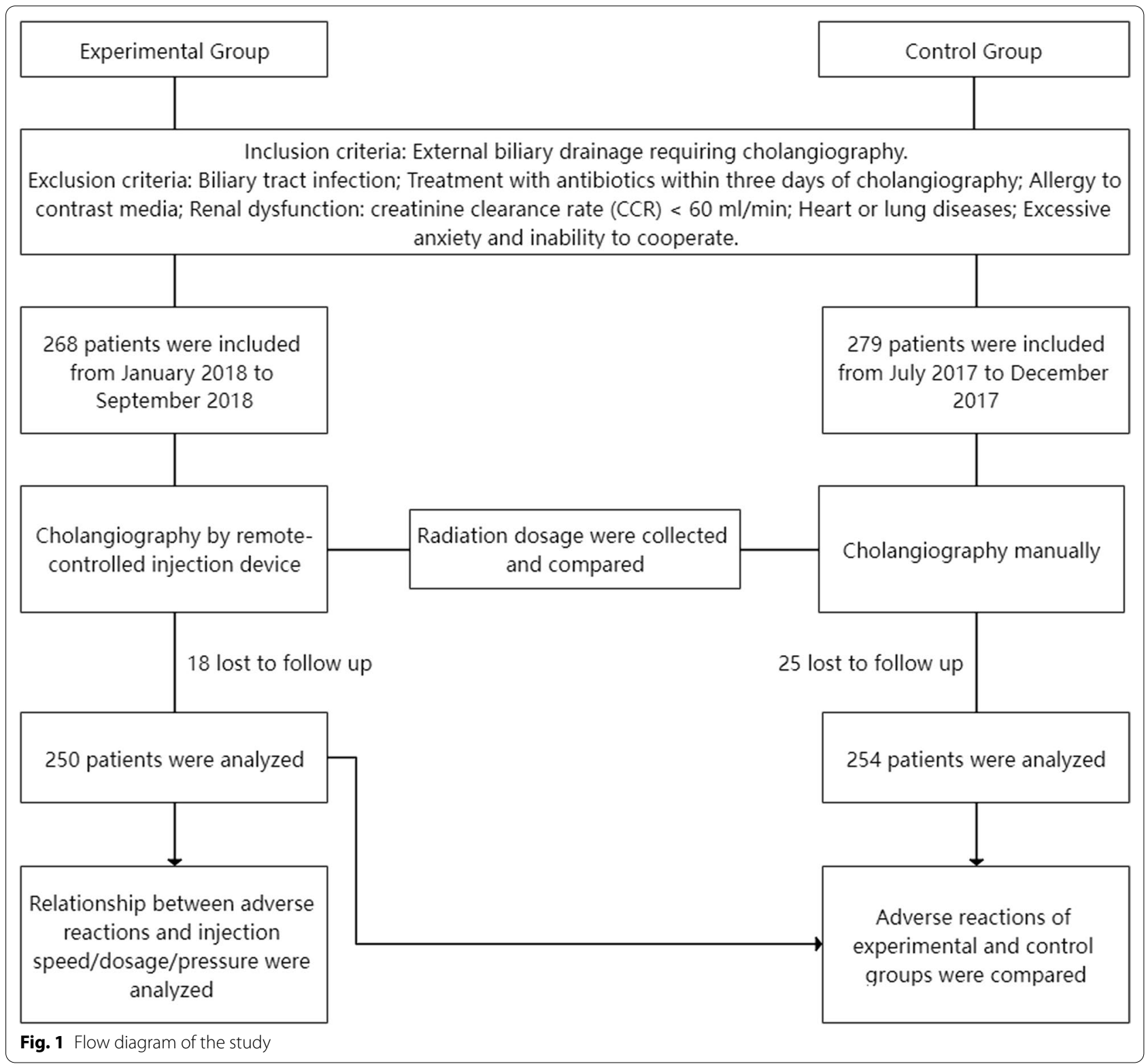


were chosen from the First Affiliated Hospital of Xi'an Jiaotong University as the control group.

Inclusion criteria:

\section{External biliary drainage requiring cholangiography}

Exclusion criteria:

1. Biliary tract infection

2. Treatment with antibiotics within three days of cholangiography

3. Allergy to contrast media

4. Renal dysfunction: creatinine clearance rate $(\mathrm{CCR})<60 \mathrm{ml} / \mathrm{min}$

5. Heart or lung diseases

6. Excessive anxiety and uncooperativeness

All protocols were approved by the Ethics Committee of the First Affiliated Hospital of Xi'an Jiaotong University (NO. XJTU1AF2015LSL-046). All procedures performed in this study involving human participants were in accordance with the ethical standards of the institutional research committee and with the 1964 Helsinki Declaration and its later amendments. The study was registered on ClinicalTrials.gov (NCT02801500, 16/6/2016). Informed consent was obtained from all participants prior to cholangiography.

\section{Equipment}

The remote-controlled injection device consists of a control terminal and an operation terminal, which communicate with each other wirelessly via Bluetooth. The structure and program were designed based on clinical operation requirements.

The control terminal consists of a wireless remotecontrol panel (Fig. 2c). Using this panel, operators can set up parameters (including injection speed, injection dose, and pressure threshold) and command the operation terminal. In addition, real-time parameters can be collected during cholangiography and exhibited to the operators, such as injection speed, pressure, and dose.

The operation terminal consists of an injection pump, a pressure sensor, and a direct-control panel (Fig. 2a, b). Using the remote-control or direct-control panel, the injection pump can replace a human operator for injecting the contrast dye. The pressure sensor is responsible for detecting the real-time injection pressure. Apart from the method of communication and the display of injection parameters, the functions of the direct-control panel are similar to those of the remote-control panel.

This device requires an extension tube to complete cholangiography. The extension tube has three ports: a syringe port, a pressure port, and a T-adapter port
(Fig. 2d). The syringe port, pressure port, and one outlet of the T-adapter port are used to connect a $50-\mathrm{ml}$ syringe, a pressure sensor, and an external biliary drainage tube separately. Another outlet of the T-adapter port can be used to connect a $20-\mathrm{ml}$ syringe for degassing the biliary drainage tube.

\section{Procedure for the experimental group (remote-controlled cholangiography injection device group) Device preparation}

The procedure involved connecting a $50-\mathrm{ml}$ syringe filled with $40 \mathrm{ml}$ of diluted contrast agent (1:1, using normal saline) to the syringe port with an extension tube and prefilling the extension tube with the contrast agent. The 50-ml syringe was then loaded onto the injection pump, and the pressure port of the extension tube was connected to the pressure sensor (Fig. 3a).

\section{Patient preparation}

Before cholangiography, patients were required to fill out a form to facilitate post-cholangiography follow-up. The patient then entered the X-ray room and stood in front of the X-ray machine. After the machine was positioned over the right upper abdomen by X-ray, the patient was adjusted to be supine with the head high $\left(20^{\circ}\right)$. The T-adapter of the extension tube was then connected to the external biliary drainage tube ( $\mathrm{T}$-tube, percutaneous transhepatic biliary drainage [PTBD], etc.), and a 20-ml syringe was used to extract the remaining air bubbles in the drainage tube and biliary tract from the $\mathrm{T}$-adapter via the extension tube.

\section{Cholangiography procedure using the remote-controlled cholangiography device}

The device was adjusted to the correct settings and connected to the power supply. The operator then left the $\mathrm{X}$-ray room and entered the observation room, opened the remote-control panel, and connected the parts of the device via Bluetooth. The injection speed, dose, and pressure threshold were set before initiation of cholangiography and could be adjusted according to the clarity of the image (Fig. 3b).

During cholangiography, the real-time injection speed, dose, and pressure were displayed on the remote-control panel, and the operator could stop or start the injection at any moment. If the feedback pressure surpassed the threshold, the equipment would activate an alarm and stop the injection automatically. After the cholangiography procedure, the operator connected the drainage tube and drainage bag for the patient. 


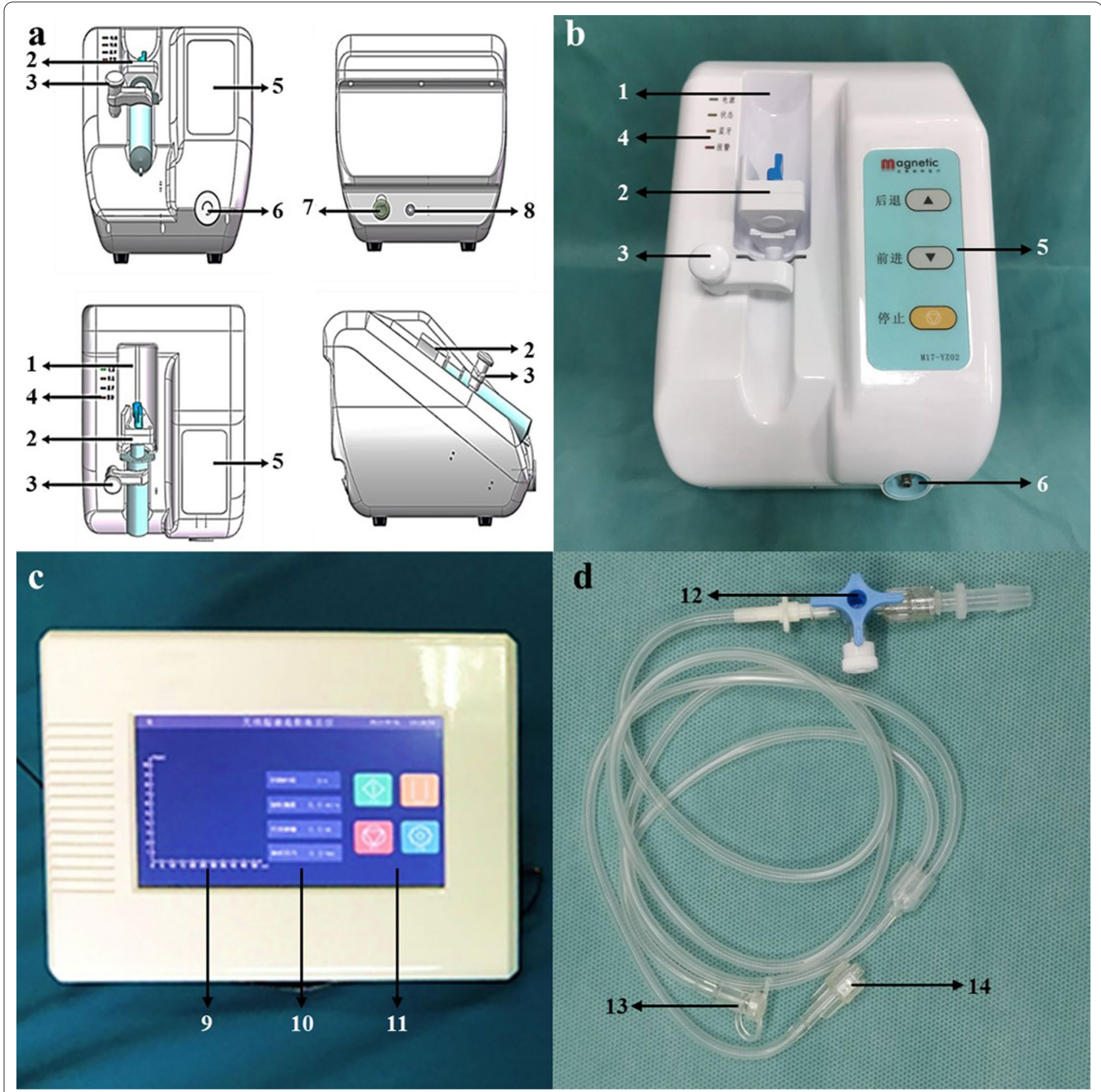

Fig. 2 Remote-controlled cholangiography injection device. a Fabrication drawing. b Operation terminal. c Control terminal. d Extension tube. (1) Syringe slot, (2) syringe pushing hand-injection pump, (3) syringe fixing arm, (4) working status indicator, (5) direct-control panel, (6) pressure sensor, (7) on/off button, (8) power port, (9) pressure curve diagram, (10) parameter setting and display buttons, (11) control buttons, (12) T-adapter port, (13) syringe port, (14) pressure port

\section{Measurement of occupational exposure}

During cholangiography, radiation was monitored by three identical radiation monitors. One was completely exposed to the radiation in the X-ray room, one was protected by a lead suit in the X-ray room, and the third was exposed to natural background radiation in the observation room.

\section{Patient follow-up}

One day after cholangiography, the patients were followed up by telephone to assess whether they had symptoms of bile duct inflammation, including fever, jaundice, and abdominal pain. 


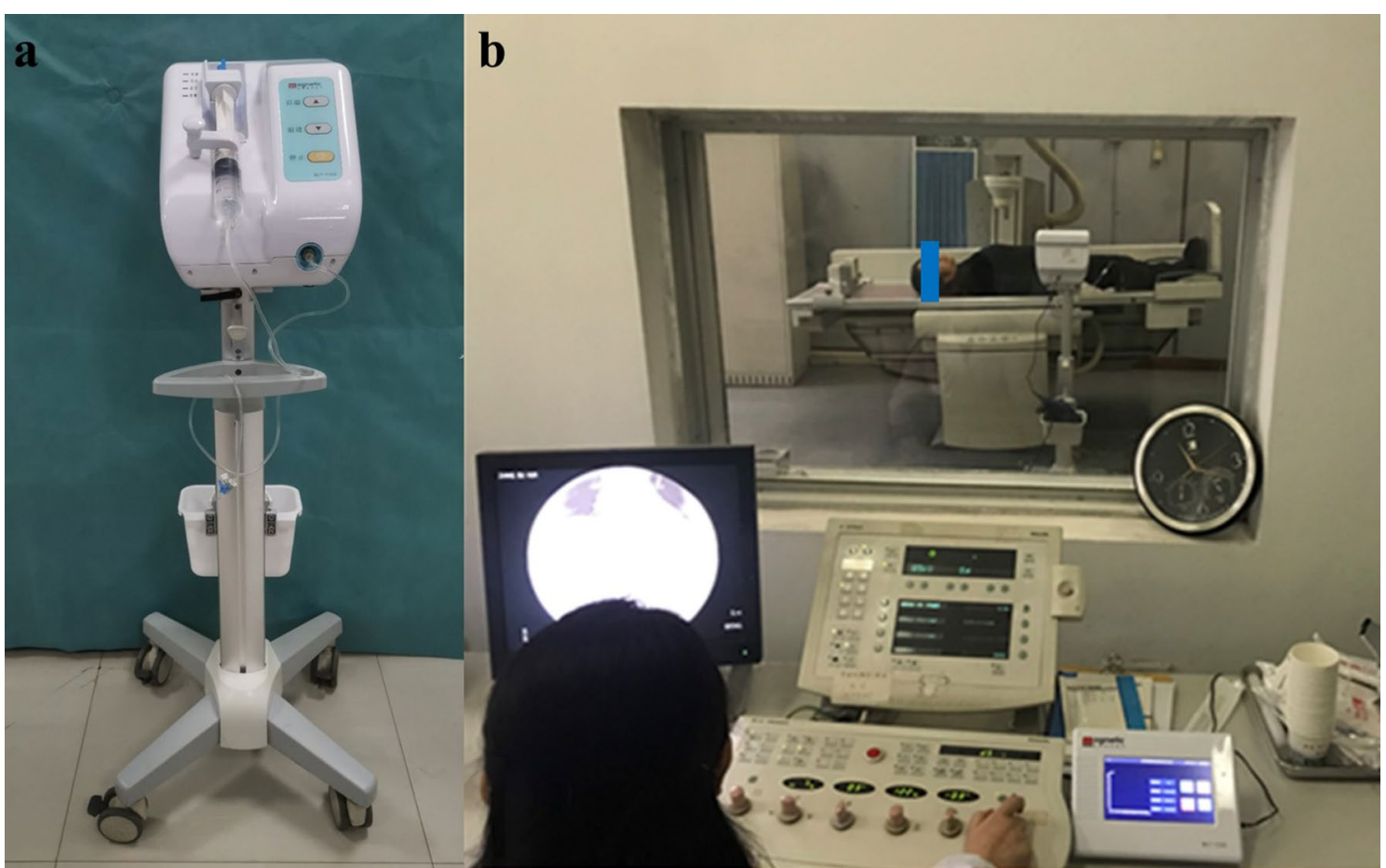

Fig. 3 Clinical application of the remote-controlled cholangiography injection device. a Preparation of the device and assembly of the operation terminal, syringe and extension tube. $\mathbf{b}$ Cholangiography using the remote-controlled device

\section{Data collection for the control group (traditional cholangiography group)}

We collected information (including demographic data, type of disease, and type of surgery) from patients undergoing traditional cholangiography from July to December 2017 at the First Affiliated Hospital of Xi'an Jiaotong University. We followed up these patients via telephone to assess whether there were post-cholangiography complications.

\section{Statistical analysis}

SPSS Statistics Software 23.0 (IBM Corporation, Armonk, NY, USA) was used for all analyses. Categorical variables are reported as numbers and proportions and were compared using chi-square or nonparametric tests as appropriate. Continuous variables are reported as the means $\pm \mathrm{SD}$ or medians (interquartile range (IQR)) and compared using the $t$ test, ANOVA, or nonparametric tests. All hypothesis tests were two-sided, and $P$ values $<0.05$ were considered statistically significant.

\section{Results}

\section{Demographic data}

From January 2018 to September 2018, 268 patients from the First Affiliated Hospital of Xi'an Jiaotong University underwent cholangiography using our remote-controlled cholangiography injection device, 18 of whom were lost to follow-up. From July 2017 to December 2017, 279 patients from the First Affiliated Hospital of Xi'an Jiaotong University underwent traditional cholangiography, 25 of whom were lost to follow-up. The demographic data of these two groups are shown in Table 1. We found no significant differences in demographic variables such as age, sex, and disease.

\section{Image quality}

Our device successfully replaced the need for a doctor to inject the contrast agent. Different kinds of cholangiography (T-tube, PTBD, endoscopic nose biliary drainage [ENBD], etc.) using this novel remote-controlled device were successfully performed in all patients. Environmental ionizing radiation did not interfere with the remote wireless transmission, which remained stable. After contrast dye injection, the biliary system was clearly displayed on the computer screen to a degree sufficient for clinical diagnosis (Fig. 4). The procedure was smooth, and all 268 patients cooperated well.

\section{Adverse reactions}

Ten of the 250 patients in the experimental group had mild postoperative adverse reactions, including fever and abdominal distension. In the control group, 254 
Table 1 Demographic data of the experimental and control groups

\begin{tabular}{lllr}
\hline & Experimental group & Control group & $P$ value \\
\hline Age (mean \pm SD/years) & $58.14 \pm 14.25$ & $56.55 \pm 14.21$ & 0.211 \\
Sex (male/female) & $127 / 123$ & $120 / 134$ & \\
Classification of diseases & & & 0.425 \\
Biliary Calculi (male/female) & $81 / 95$ & $90 / 115$ & 0.678 \\
Hepato-Bilio-Pancreatic Cancer (male/female) & $18 / 13$ & $15 / 9$ & 0.739 \\
Liver transplantation (male/female) & $19 / 4$ & $11 / 3$ & $>0.999$ \\
Others* (male/female) & $11 / 10$ & $5 / 6$ & 0.710 \\
\hline
\end{tabular}

*Others include patients who underwent a second operation, choledochojejunostomy, etc.

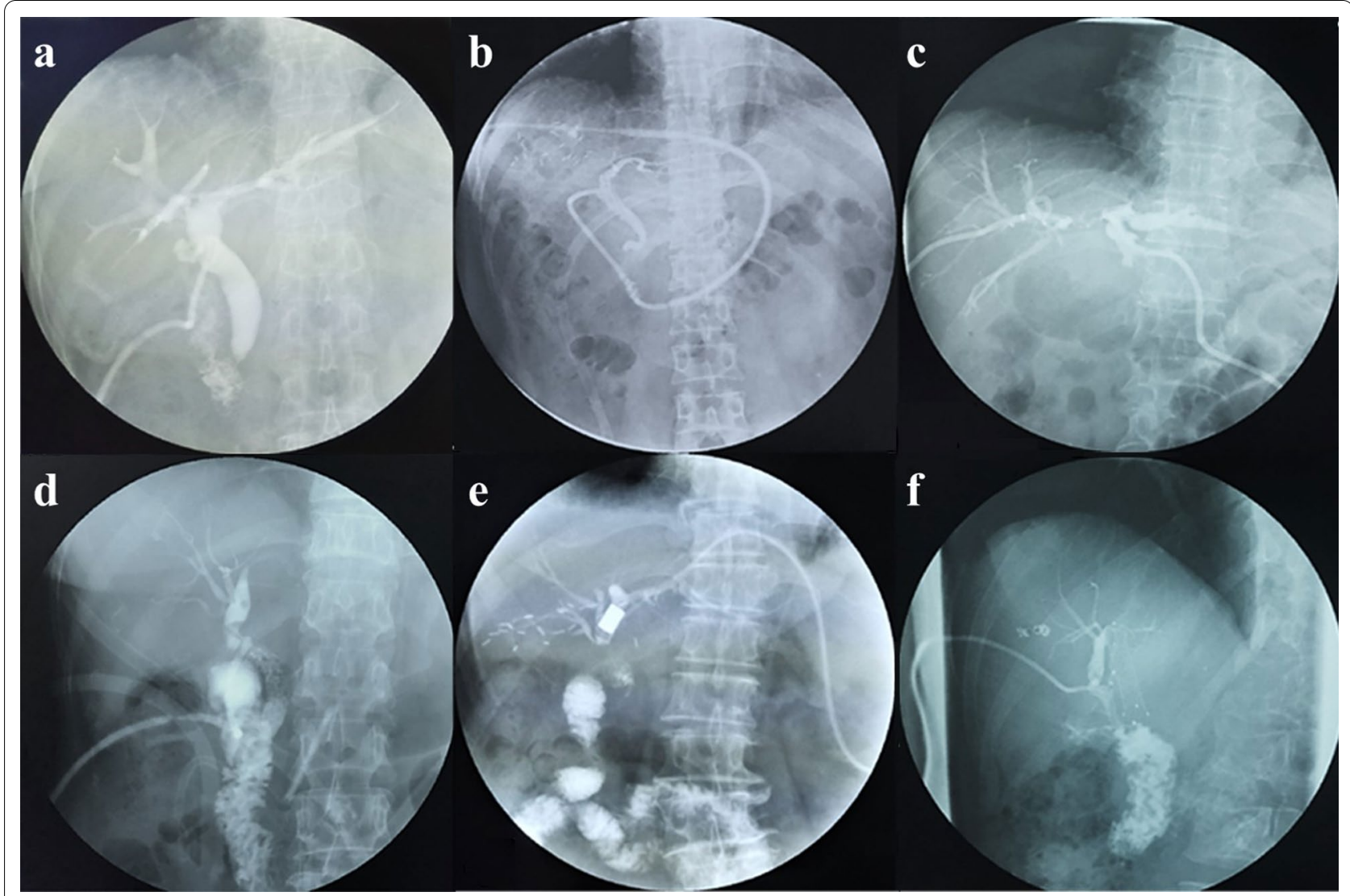

Fig. 4 Results of remote-controlled cholangiography. a Normal biliary system. The common bile duct, intrahepatic bile duct and part of the intestinal mucosa are exhibited. b Right hemihepatectomy. The common bile duct and left hepatic duct are well visualized. $\mathbf{c}$ Hilar cholangiocarcinoma. The left and right hepatic ducts and their branches can be fully visualized through PTCD. The common hepatic duct, common bile duct and duodenum are not visualized. $\mathbf{d}$ Multiple biliary calculus. Multiple filling defects of the biliary system are displayed. Dilation and filling defects of the right hepatic duct can be seen. e Magnetic compressing biliary-intestinal anastomosis. The bile duct was connected to the intestine by a pair of magnets. The biliary system and intestinal mucosa can be clearly seen. f Postorthotopic liver transplantation. The biliary system is visualized well, and the anastomosis of the common bile duct is unobstructed

patients were followed up by telephone, 31 of whom reported mild postoperative adverse reactions, including fever and abdominal distension. The incidence of adverse reactions in the experimental group was significantly lower than that in the control group (4.17\% vs. $13.9 \%, P=0.001$ ) (Table 2 ).

To explore the factors affecting adverse reactions after cholangiography, we analyzed the relationship 
Table 2 Adverse reactions of the experimental and control groups

\begin{tabular}{|c|c|c|c|c|}
\hline \multirow[t]{2}{*}{ Diseases } & \multirow[t]{2}{*}{ Groups } & \multicolumn{2}{|l|}{ Numbers } & \multirow[t]{2}{*}{$P$ value } \\
\hline & & With adverse reactions & Without adverse reactions & \\
\hline \multirow[t]{2}{*}{ Biliary Calculi } & Experimental group & 8 & 168 & 0.008 \\
\hline & Control group & 25 & 180 & \\
\hline \multirow[t]{2}{*}{ Hepato-Bilio-Pancreatic Cancer } & Experimental group & 1 & 30 & 0.086 \\
\hline & Control group & 4 & 20 & \\
\hline \multirow[t]{2}{*}{ Liver transplantation } & Experimental group & 1 & 22 & $>0.999$ \\
\hline & Control group & 1 & 13 & \\
\hline \multirow[t]{2}{*}{ Other } & Experimental group & 0 & 21 & 0.111 \\
\hline & Control group & 2 & 9 & \\
\hline \multirow[t]{2}{*}{ Total } & Experimental group & 10 & 240 & 0.001 \\
\hline & Control group & 31 & 223 & \\
\hline
\end{tabular}

Table 3 Relationship between adverse reactions and injection parameters

\begin{tabular}{llll}
\hline Groups & \multicolumn{2}{l}{ Numbers } & P value \\
\cline { 2 - 3 } & $\begin{array}{l}\text { With adverse } \\
\text { reactions }\end{array}$ & $\begin{array}{l}\text { Without } \\
\text { adverse } \\
\text { reactions }\end{array}$ & \\
\hline Injection pressure $(\mathrm{kPa})$ & & 132 & $<0.001$ \\
$0-3$ & 2 & 70 & \\
$3.1-7$ & 1 & 10 & \\
$7.1-10$ & 1 & 27 & \\
$>10$ & 6 & & \\
Injection speed $(\mathrm{ml} / \mathrm{s})$ & & 42 & \\
$0.1-0.3$ & 5 & 134 & \\
$0.4-0.7$ & 3 & 64 & 0.618 \\
$0.8-1$ & 2 & & \\
Injection dose $(\mathrm{ml})$ & & 57 & \\
$<20$ & 2 & 94 & \\
$20-30$ & 5 & 3 & \\
$>30$ & 3 & & \\
\hline
\end{tabular}

between the adverse reactions and injection parameters (including speed, dose, and pressure) in the experimental group. We found that the injection pressure had a significant effect on the occurrence of postoperative complications (Table 3). With increasing injection pressure, the incidence of adverse reactions also increased (injection pressures: $0-3 \mathrm{kPa} ; 3.1-7 \mathrm{kPa} ; 7.1-$ $10 \mathrm{kPa}$; $10 \mathrm{kPa}$; incidence: $1.52 \% ; 1.41 \% ; 10.0 \% ; 22.2 \%$, respectively; $P<0.001)$. In contrast to the injection pressure, when the injection speed was $0.1-0.3 \mathrm{ml} / \mathrm{s}$, the incidence of adverse reactions was higher than in the other two high injection speed groups (injection speeds: $0.1-0.3 \mathrm{ml} / \mathrm{s} ; 0.4-0.7 \mathrm{ml} / \mathrm{s} ; 0.8-1.0 \mathrm{ml} / \mathrm{s}$; incidence: $11.9 \%$; $2.24 \%$; $3.13 \%$, respectively; $P=0.035$ )
(Table 3). However, further analysis revealed that when the injection speed was $0.1-0.3 \mathrm{ml} / \mathrm{s}$, the injection pressure used for all five patients who experienced adverse reactions was greater than $10 \mathrm{kPa}$. The injection dose was not a risk factor for adverse reactions.

\section{Radiation}

The radiation doses from three different sources were collected, including natural background radiation $\left(R_{0}\right)$, radiation from cholangiography of exposed areas $\left(R_{1}\right)$ and radiation from cholangiography of protected areas $\left(R_{2}\right)$. The differences between the doses for these three kinds of radiation were significant $\left(R_{0}\right.$ vs. $R_{1}$ vs. $R_{2} ; 0.01$ [IQR 0.00, 0.02]; vs. 0.16 [IQR 0.07, 0.16]; vs. 3.09 [IQR $1.67,4.85] \mu \mathrm{Sv}$, respectively; $P<0.001)$. The radiation dose detected in the observation room was significantly lower than that detected in the zone protected by the lead suit.

\section{Discussion}

Cholangiography is an important examination in biliary diseases. However, it must be performed under X-ray, and occupational exposure for operators is unavoidable $[14-16,19,20]$. Additionally, cholangiography requires the clinician to manually inject contrast dye into the biliary tract. As a result, the injection speed and pressure can be variable, and the intrabiliary pressure is not monitored, which could lead to adverse reactions [21]. The rapid development of remote-controlled technology has led to its wide application in clinical practice, including in remote-controlled injection systems [22-24] and remotecontrolled vascular interventional robots [25-27]. However, studies on remote-controlled cholangiography devices are scarce. In this study, a remote-controlled cholangiography injection device was developed and applied in the clinic. The feasibility, security, and efficacy of this device were verified. 
In this study, we analyzed and quantified two major defects of traditional cholangiography by collecting clinical data, including occupational exposure and adverse reactions. For occupational exposure, we found that although wearing a lead suit could reduce the radiation dose significantly $\left(\mathrm{R}_{1}\right.$ vs. $\mathrm{R}_{2} ; 0.16$ [IQR $0.07,0.16$ ] vs. 3.09 [IQR $1.67,4.85] \mu \mathrm{Sv} ; P<0.001$ ), it was unable to eliminate occupational exposure completely $\left(\mathrm{R}_{0}\right.$ vs. $\mathrm{R}_{1} ; 0.01$ [IQR $0.00,0.02]$ vs. 0.16 [IQR $0.07,0.16] \mu$ Sv; $P<0.001$ ). Furthermore, wearing a heavy lead suit undoubtedly increases the workload and affects the operation. We therefore proposed that to eliminate occupational exposure, remote-control measures must be adopted to replace the wearing of a lead suit. In this study, the Bluetooth signal of the remote-controlled cholangiography injection device could be transmitted stably in the $\mathrm{X}$-ray environment and assisted in performing remotecontrolled cholangiography sensitively, accurately, and without delay. Therefore, this device could satisfy the technical requirements of cholangiography and avoid the radiation exposure from traditional cholangiography. Additionally, we believe that the surgical operation will not affect the functioning of this equipment. Thus, intraoperative cholangiography can be realized both in open surgery and laparoscopically, and the only requirement is that the extension tube must be kept sterile.

Due to the anatomical relationship between the bile duct and the hepatic sinus, when biliary pressure increases, bile-blood reflux occurs [28]. If there are bacteria in the bile, they would reflux into the blood and could cause bacteremia [29]. However, in traditional cholangiography, the injection pressure is manually controlled and was not monitored. Therefore, fever and chills after cholangiography are common [17]. In this study, the incidence of adverse reactions in the experimental group was significantly lower than that in the control group ( $4.17 \%$ vs. $13.9 \%, P=0.001)$. In the experimental group, the contrast dye was injected by a machine, the injection speed was stable, and the injection pressure was monitored. Therefore, an acute increase in the injection pressure was prevented. The existence of a pressure threshold further assisted in avoiding an acute increase in the injection pressure, which was difficult in the control group. Thus, in the experimental group, the incidence of adverse reactions could be reduced relative to that of traditional cholangiography.

We analyzed the relationship between adverse reactions and injection parameters (including speed, dose, and pressure) collected by our remote-controlled device and found that injection pressure had a significant effect on the occurrence of postoperative complications. With increasing injection pressure, the incidence of adverse reactions also increased. Of the 10 patients who experienced adverse reactions after cholangiography, eight had injection pressures of more than $10 \mathrm{kPa}$. In contrast to the injection pressure, when the injection speed was $0.1-0.3 \mathrm{ml} / \mathrm{s}$, the incidence of adverse reactions was higher than in the other two high injection speed groups. However, further analysis revealed that when the injection speed was $0.1-0.3 \mathrm{ml} / \mathrm{s}$, the injection pressure used for all five patients who had adverse reactions was greater than $10 \mathrm{kPa}$. This further confirmed that high injection pressure was a proximate cause of adverse reactions, while the injection speed could influence postoperative complications by affecting the injection pressure. Good control of the injection pressure can reduce adverse reactions associated with cholangiography. In this study, we used a pressure sensor that displayed the real-time injection pressure during cholangiography, allowing the operator to adjust the injection speed according to the changing injection pressure. We proposed that to reduce postoperative complications in cholangiography, the injection pressure should be controlled to within $10 \mathrm{kPa}$.

This study has several limitations that need to be mentioned here. First, this research was limited to a single center, and further large and multi-institutional research is needed. Second, because of the use of an extension tube, the obtained injection pressure was not the exact pressure in the bile duct, although the device could accurately indicate the change in pressure in the bile tract. Third, although the study was of a prospective nature, the learning and trial periods of the device delayed the research on the experimental group. Thus, the control and experimental groups were investigated at different times, potentially resulting in bias or misunderstanding.

\section{Conclusions}

In conclusion, clinical application proved that the remote-controlled cholangiography injection device could clearly display the biliary system structure, eliminate occupational exposure for the operator, and reduce adverse reactions by controlling the injection pressure to within $10 \mathrm{kPa}$. The device is the first remote-controlled cholangiography system in China. The device could replace traditional cholangiography and is expected to be of value in the clinic.

\section{Abbreviations \\ ANOVA: Analysis of variance; CCR: Creatinine clearance rate; CT: Computed tomography; ENBD: Endoscopic nose biliary drainage; IQR: Interquartile range; MRCP: Magnetic resonance cholangiopancreatography; PTBD: Percutaneous transhepatic biliary drainage.}

\section{Acknowledgements}

The authors thank all the staff at the National Local Joint Engineering Research Center for Precision Surgery and Regenerative Medicine for their help and provision of facilities for performing this study. 


\section{Authors' contributions}

All the authors helped perform the research; HYZ and $Y L$ conceived and designed the experiments; $\mathrm{HC}$ hen and LYS han contributed to the experiment; HC, LYS, HYZ, TM and YW collected and analyzed the data; HC, DHD, TM and $Y W$ contributed to manuscript writing. HYZ contributed to critical revision of the manuscript. All authors read and approved the final manuscript.

\section{Funding}

This research was supported by Fundamental Research Funds for the Central Universities (xjh012019052).

\section{Availability of data and materials}

The clinical datasets generated and analyzed during the study are not publicly available due to privacy issues but are available from the corresponding author on reasonable request.

\section{Declarations}

\section{Ethics approval and consent to participate}

Clinical trial registration numbers and date of registration: ClinicalTrials.gov ID: NCT02801500 (16/6/2016); Unique Protocol ID: XJTU1AF-CRF-2015-001 (05/29/2016). Approval number of the institutional review board: XJTU1AF2015LSL-046 (Ethics Committee of the First Affiliated Hospital of Xi'an Jiaotong University). All protocols were approved by the Ethics Committee of the First Affiliated Hospital of Xi'an Jiaotong University (No. XJTU1AF2015LSL-046). All procedures performed in this study involving human participants were in accordance with the ethical standards of the institutional research committee and with the 1964 Helsinki Declaration and its later amendments.

\section{Consent for publication}

Not applicable.

\section{Competing interests}

The authors declare no competing interests.

\section{Author details}

${ }^{1}$ National Local Joint Engineering Research Center for Precision Surgery and Regenerative Medicine, First Affiliated Hospital of Xi'an Jiaotong University, Xi'an 710061, China. ${ }^{2}$ Department of Anesthesiology, First Affiliated Hospital of Xi'an Jiaotong University, Xi'an 710061, China. ${ }^{3}$ Department of Hepatobiliary Surgery, The First Affiliated Hospital of Kunming Medical University, Kunming 650032, China. ${ }^{4}$ Department of Hepatobiliary Surgery, First Affiliated Hospital of Xi'an Jiaotong University, Xi'an 710061, China.

Received: 27 July 2021 Accepted: 24 December 2021

Published online: 07 January 2022

\section{References}

1. Glasgow RE, Cho M, Hutter MM, Mulvihill SJ. The spectrum and cost of complicated gallstone disease in California. Arch Surg. 2000;135:1021-5 (discussion 5-7)

2. Chehade M, Kakala B, Sinclair JL, Pang T, Al Asady R, Richardson A, et al. Intraoperative detection of aberrant biliary anatomy via intraoperative cholangiography during laparoscopic cholecystectomy. ANZ J Surg. 2019;89:889-94.

3. Edo H, Sekiguchi R, Edo N, Kajiyama A, Nagamoto M, Gomi T. Evaluation of biliary anatomy in the caudate lobe using drip infusion cholangiographycomputed tomography. Abdom Radiol. 2019;44:886-93.

4. Ye S, Dong JH, Duan WD, Ji WB, Liang YR. The preliminary study on procurement biliary convergence from donors with complicated bile duct variant in emergency right lobe living donor liver transplantation. J Clin Exp Hepatol. 2017;7:33-41.

5. Marolf AJ. Diagnostic imaging of the hepatobiliary system: An update. Vet Clin N Am Small Anim Pract. 2017;47:555-68.

6. Larson MM. Ultrasound imaging of the hepatobiliary system and pancreas. Vet Clin N Am Small Anim Pract. 2016;46(453-80):v-vi.

7. Kim JH. Clinical feasibility and usefulness of CT fluoroscopy-guided percutaneous transhepatic biliary drainage in emergency patients with acute obstructive cholangitis. Korean J Radiol. 2009;10:144-9.
8. Kim HJ, Kim AY, Hong SS, Kim MH, Byun JH, Won HJ, et al. Biliary ductal evaluation of hilar cholangiocarcinoma: three-dimensional direct multidetector row CT cholangiographic findings versus surgical and pathologic results-feasibility study. Radiology. 2006;238:300-8.

9. Wallner BK, Schumacher KA, Weidenmaier W, Friedrich JM. Dilated biliary tract: evaluation with MR cholangiography with a T2-weighted contrastenhanced fast sequence. Radiology. 1991;181:805-8.

10. Romagnuolo J, Bardou M, Rahme E, Joseph L, Reinhold C, Barkun AN. Magnetic resonance cholangiopancreatography: a meta-analysis of test performance in suspected biliary disease. Ann Intern Med. 2003;139:547-57.

11. Lehrskov LL, Westen M, Larsen SS, Jensen AB, Kristensen BB, Bisgaard T. Fluorescence or X-ray cholangiography in elective laparoscopic cholecystectomy: a randomized clinical trial. Br J Surg. 2020;107:655-61.

12. Garg B, Rastogi R, Gupta S, Rastogi H, Garg H, Chowdhury V. Evaluation of biliary complications on magnetic resonance cholangiopancreatography and comparison with direct cholangiography after living-donor liver transplantation. Clin Radiol. 2017;72:518.e9-e15.

13. Choi JY, Kim MJ, Lee JM, Kim KW, Lee JY, Han JK, et al. Hilar cholangiocarcinoma: role of preoperative imaging with sonography, MDCT, MRI, and direct cholangiography. AJR Am J Roentgenol. 2008;191:1448-57.

14. Hyun SJ, Kim KJ, Jahng TA, Kim HJ. Efficiency of lead aprons in blocking radiation-How protective are they? Heliyon. 2016;2:e00117.

15. Mori H, Koshida K, Ishigamori O, Matsubara K. Evaluation of the effectiveness of X-ray protective aprons in experimental and practical fields. Radiol Phys Technol. 2014;7:158-66.

16. Jacob S, Michel M, Spaulding C, Boveda S, Bar O, Brézin AP, et al. Occupational cataracts and lens opacities in interventional cardiology $\left(\mathrm{O}^{\prime} \mathrm{CLOC}\right.$ study): are X-Rays involved? Radiation-induced cataracts and lens opacities. BMC Public Health. 2010;10:537.

17. Wills VL, Gibson K, Karihaloot C, Jorgensen JO. Complications of biliary T-tubes after choledochotomy. ANZ J Surg. 2002:72:177-80.

18. Zhu H, Dong D, Luo Y, Zhang J, Ren F, Zhang H, et al. A novel remotecontrolled injection device for t-tube cholangiography: a feasibility study in Canines. Med Sci Monit. 2019;25:2016-23.

19. Picano $E$, Vano $E$. The radiation issue in cardiology: the time for action is now. Cardiovasc Ultrasound. 2011;9:35.

20. Domienik J, Bissinger A, GrabowiczW, Jankowski Ł, Kręcki R, Makowski M, et al. The impact of various protective tools on the dose reduction in the eye lens in an interventional cardiology-clinical study. J Radiol Prot. 2016;36:309-18.

21. Harvey MH, Wedgwood KR, Austin JA, Reber HA. Pancreatic duct pressure, duct permeability and acute pancreatitis. Br J Surg. 1989;76:859-62.

22. Rosenhamer $\mathrm{G}$. Remote-controlled injection system for repeated dye dilution studies. Scand J Clin Lab Invest. 1968;21:347-50.

23. Wang J, Liu $H$, Zhang $K$, Li B, Yang $H$, Wang $H$, et al. Reducing radiation exposure during kyphoplasty with the use of a remote control injection system: a prospective study. Spine (Phila Pa). 1976;2015(40):E127-32.

24. Jin P, Liu X, Li M, Sun G. Clinical experience using a remote control injection system in vertebroplasty: feasibility, safety, and cement leakage of osteoporotic and malignant compression fractures. Clin Spine Surg. 2017;30:E305-9

25. Da L, Zhang D, Wang T. Overview of the vascular interventional robot. Int J Med Robot. 2008;4:289-94.

26. Bao X, Guo S, Xiao N, Li Y, Yang C, Shen R, et al. Operation evaluation inhuman of a novel remote-controlled vascular interventional robot. Biomed Microdevices. 2018;20:34.

27. Feng Z, Bian G, Xie X, Hao J, Gao Z, Hou Z. Preliminary study for motion scaling based control in minimally invasive vascular interventional robot. In: 2015 37th annual international conference of the IEEE engineering in medicine and biology society (EMBC). Milan, Italy. IEEE; 2015, p 4898-901

28. Mukewar S, Gorospe EC, Knipschield MA, Bingener J, Gostout C. Effects of carbon dioxide insufflation during direct cholangioscopy on biliary pressures and vital parameters: a pilot study in porcine models. Gastrointest Endosc. 2017;85:238-42.e1

29. Sheen-Chen SM, Cheng YF, Chou FF, Lee TY. Postoperative T-tube cholangiography: is routine antibiotic prophylaxis necessary? A prospective, controlled study. Arch Surg. 1995;130:20-3.

\section{Publisher's Note}

Springer Nature remains neutral with regard to jurisdictional claims in published maps and institutional affiliations. 